\title{
NOTE
}

\section{The Effect of Orchiectomy and Androgen Supplement on the Adrenal Cortex and Medulla of Rats}

\author{
Kazuo KUBOTA and Mitsuo SUZUKI \\ Department of Physiology, Institute of Endocrinology, \\ Gunma University, Maebashi 371
}

\begin{abstract}
Synopsis
Orchiectomy in rats resulted in retarded body growth, and an increase in thymus and adrenal weights. With concomitant increase in adrenal cholesterol and corticosterone contents, adrenal norepinephrine, a minor component of medullary hormones, and the total catecholamine contents were also increassed by the operation. These changes were prevented or to be recovered by $2 \mathrm{mg}$ of testosterone propionate supplement $(1 \mathrm{mg}$ per rat per week for 2 weeks). A conventional estimation of the cortical and the medullary volumes revealed that orchiectomy caused a marked increase in the whole adrenal and cortical volumes and also an increase in the medullary volume, although it was not statistically significant. The data suggest that androgen in male rat affects not only the adrenal cortex but also the medulla.
\end{abstract}

It is well attested that adrenal function is affected by gonadal hormones. Gonadectomy in male rats increases adrenal weight and, on the other hand, in female rats decreases the weight (Kitay, 1963b). The effect and mode of action of gonadal hormones has been extensively studied by Kitay and his group (Kitay, 1961; Kitay, 1963c; Kitay, 1963a; Colby et al., 1972). However, so far no attention has been paid to change in the adrenal medulla brough about by the hormones, which is surrounded by the cortex and is functionally different from the cortex.

In the present paper, we describe the biochemical and morphological changes in rat adrenal medulla following orchiectomy, with concurrent changes in the cortex.

Received for publication February 21, 1974.

* The expenses for this study were supported in part by a grant from the Ministry of Education, Japan.

\section{Materials and Methods}

Animals

Male Wistar rats, weighing 100 to $150 \mathrm{~g}$ at the beginning of the experiment were used. The animals were housed in a temperature controlled $\left(25 \pm 1^{\circ} \mathrm{C}\right)$, and artificially illuminated (light on from 7 AM until 7 PM daily) room, and maintained on pellets of Oriental Yeast Co. and water ad libitum. The animals were divided into three groups. The first group (I) was sham-operated animals as a control. The second (II) was orchiectomized animals. And the third (III) was orchiectomized and testosterone propionate (T. P.) supplemented animals. Testosterone propionate (1 mg in $0.1 \mathrm{ml}$ of cotton seed oil) was injected subcutaneously into the back of the neck once a week for 2 weeks. The animals of the first and second groups were similarly given the solvent.

In order to stabilize the pituitary-adrenal axis, the animals were treated in advance with dexamethazone $(0.2 \mathrm{mg}$ per rat at $9.30 \mathrm{AM})$ and anaesthetized with sodium pentobarbiturate $(0.1 \mathrm{mg}$ per rat 1.00 PM) (Tanaka et al., 1968). Shortly after anaesthesia, the animals were decapitated by guillotine and blood samples were collected.

Abbreviation used. T, P.: testosterone propionate, 


\section{Chemical Assay}

The right adrenal gland was quickly removed, weighed and used for corticosterone assay. Corticosterone concentration in the adrenal and serum was determined after the method of Moncloa et al. (Moncloa et al., 1959) with the use of a Farrand MK 1 Spectrofluorometer. The left adrenal gland was used for cholesterol and catecholamine assays. The gland was homogenized with $1 \mathrm{~m} l$ of the upper layer of a mixture of one part of $0.4 \mathrm{~N}$ perchloric acid and one part of chloroform-methanol $(2: 1, \mathrm{v} / \mathrm{v})$ in a small glass homogenizer. After centrifugation at 3,000 rpm for $5 \mathrm{~min}$ in a refrigerated centrifuge the supernatant was removed. Extraction with $0.5 \mathrm{ml}$ of the upper layer was carried out twice, after which the precipitate in the glass homogenizer was extracted with $1 \mathrm{~m} l$ of the lower layer from the $0.4 \mathrm{~N}$ perchloric acid-chloroform-methanol mixture, followed by extraction twice with $1.0 \mathrm{~m} l$ of the lower layer. The combined latter extract was back-extracted with 1 $\mathrm{m} l$ of the upper layer. Finally the volume of both the combined extracts was approximately $2.8 \mathrm{ml}$. The upper layer extract was used for catecholamines assay after a slightly modified method of Crout (Crout, 1962), in which $0.3 \%$ ascorbic acid solution was substituted for the $0.4 \%$ solution in the original method. The lower layer extract was employed to determine cholesterol concentration (Clark et al., 1968).

\section{Histological method, a simple approximation for an adrenal morphometry}

In this experiment, an attempt was made to find change in the volume of adrenal glands, both the cortex and medulla by orchiectomy. The right adrenals were fixed in Bouin's solution and sectioned along the major axis at $10 \mu$ and mounted serially. The mounted sections were stained with hematoxylin-eosin. The measurement of the longest major and minor axes of the adrenal and medulla in the serial section was taken from an enlarged photoprint. The approximate volume of the two glands fused to each other was estimated on the basis of the following three assumptions; first the adrenal gland has a rotatory ellipsoid shape, secondly the medulla has a shape similar to that of the whole adrenal, and thirdly, the medullary density is the same as that of the cortex.

Thus, the volume $\left(\mathrm{mm}^{3}\right)$ of the cortex and the medulla was calculated from the equation

$$
\begin{aligned}
& \text { Volume }_{\text {cortex }}=\frac{4}{3} \pi\left(a_{1} b_{1}^{2}-a_{2} b_{2}^{2}\right) \\
& \text { Volume }_{\text {medulia }}=\frac{4}{3} \pi a_{2} b_{2}^{2}
\end{aligned}
$$

where $a_{1}$ and $a_{2}$ are halves of the major axes ( $\left.\mathrm{mm}\right)$ and $b_{1}$ and $b_{2}$ are halves of the minor axes $(\mathrm{mm})$ of the whole adrenal and medulla respectively.

\section{Results}

\section{Effects of orchiectomy and androgen sup- plement on the adrenal function}

Although orchiectomized rats grew at a slower rate $(+41 \%$ of the initial body weight $)$ than that of the control animals $(+70 \%)$, adrenal and thymus weights were markedly increased (Table 1). The T.P. supplement prevented these changes after orchiectomy.

Serum corticosterone concentration $(\mu \mathrm{g} /$ $100 \mathrm{~m} l$ plasma) did not change after orchi-

Table 1. Effect of orchiectomy and T.P. supplement on the pituitary, adrenal and thymus weights

\begin{tabular}{lccc}
\hline \hline & $\begin{array}{c}\text { I. Sham-operated } \\
\text { (control) }\end{array}$ & II. Orchiectomized & $\begin{array}{c}\text { III. Orchiectomized- } \\
\text { T.P. supplemented }\end{array}$ \\
\hline No. of rats & 9 & 9 & 8 \\
Body weight (g) & $206.7 \pm 4.7^{* \mathrm{c}}$ & $180.9 \pm 3.1$ & $196.9 \pm 9.7$ \\
$\begin{array}{l}\text { Increase in body weight } \\
\text { (\% of initial weight) }\end{array}$ & $169.9 \pm 1.9^{\mathrm{c}}$ & $140.9 \pm 2.9$ & $154.6 \pm 2.2^{\mathrm{b}}$ \\
Pituitary weight (mg) & $5.74 \pm 0.25$ & $5.73 \pm 0.20$ & $5.20 \pm 0.34$ \\
Total adrenal weight (mg) & $39.77 \pm 1.38^{\mathrm{a}}$ & $50.33 \pm 1.77$ & $40.17 \pm 1.92^{\mathrm{b}}$ \\
$\quad$ right adrenal (mg) & $18.86 \pm 0.83^{\mathrm{a}}$ & $25.11 \pm 1.14$ & $18.90 \pm 1.23^{\mathrm{b}}$ \\
$\quad$ left adrenal (mg) & $20.91 \pm 0.78^{\mathrm{b}}$ & $25.21 \pm 0.78$ & $21.27 \pm 1.37^{\mathrm{a}}$ \\
Thymus weight (mg) & $390.5 \pm 17.1^{\mathrm{c}}$ & $544.4 \pm 28.6$ & $367.5 \pm 28.63^{\mathrm{b}}$ \\
\hline
\end{tabular}

* Mean \pm S.E.

$\mathrm{a}, \mathrm{b}, \mathrm{c}$, Significantly different from $\mathrm{II}, \mathrm{p}<0.02,0.01$ and 0.001 respectively. 
ectomy and T.P. supplement. The adrenal corticosterone concentration $(\mu \mathrm{g} / 100 \mathrm{mg}$ adrenal weight) also showed no change after orchiectomy and T.P. supplement (Table 2), but, the adrenal corticosterone content was increased by $42 \%$ of control after orchiectomy and T.P. supplement tended to prevent the increase (Table 2).

The mean adrenal cholesterol as a representative substance in the cortex was clearly increased by $80 \%$ of control and by $50 \%$ of control per $\mathrm{mg}$ adrenal weight after orchiectomy, and the increase was prevented by T.P. supplement (Table 2). The content of epinephrine, a major component in rat medullary hormones was not changed. On the other hand, after orchiectomy, the mean norepinephrine content was increased by $86 \%$ of control and by $60 \%$ of control expressed in terms of $\mu \mathrm{g} / \mathrm{mg}$ adrenal weight, almost the same as in the case of cholesterol (Table 3). The total catecholamine content was also increased after the operation, though the ratio to the norepinephrine content was not significantly changed.

Change in the volume of the adrenal cortex and medulla after orchiectomy

Figure 1 shows a typical example of the adrenals from normal and orchiectomized rats. The clear hypertrophy of the adrenal from the latter animals was observed (Fig. 1B), compared with that of the control (Fig. 1A). The hypertrophy in Zona reticularis

Table 2. Effect of orchiectimy and T.P. supplement on plasma and adrenal corticosterone and cholesterol contents

\begin{tabular}{|c|c|c|c|}
\hline & $\begin{array}{l}\text { I. Sham-operated } \\
\text { (control) }\end{array}$ & II. Orchiectomized & $\begin{array}{l}\text { III. Orchiectomized- } \\
\text { T.P. supplemented }\end{array}$ \\
\hline No of rats & 9 & 9 & 8 \\
\hline $\begin{array}{l}\text { Plasma corticosterone } \\
(\mu \mathrm{g} / 100 \mathrm{~m} l)\end{array}$ & $3.99 \pm 0.39 *$ & $4.00 \pm 0.43$ & $4.56 \pm 0.51$ \\
\hline Adrenal corticosterone $(\mu \mathrm{g})$ & $1.016 \pm 0.055^{\mathrm{a}}$ & $1.444 \pm 0.127$ & $1.228 \pm 0.058$ \\
\hline ( $\mu \mathrm{g} / \mathrm{mg}$ adrenal $)$ & $0.0541 \pm 0.0023$ & $0.0575 \pm 0.0046$ & $0.0650 \pm 0.0032$ \\
\hline Cholesterol $(\mu \mathrm{g})$ & $347.6 \pm 21.7^{\mathrm{b}}$ & $631.8 \pm 35.4$ & $317.8 \pm 16.9^{\mathrm{b}}$ \\
\hline$(\mu \mathrm{g} / \mathrm{mg}$ adrenal) & $\pm 0.97^{\mathrm{b}}$ & \pm 1.55 & $\pm 1.02^{b}$ \\
\hline
\end{tabular}

* Mean \pm S.E.

a, b, Significantly different from II, $\mathrm{p}<0.01$ and 0.001 respectively.

Table 3. Effect of orchiectomy and T.P. supplement on adrenal catecholamine contents

\begin{tabular}{|c|c|c|c|}
\hline & $\begin{array}{l}\text { I. Sham-operated } \\
\text { (control) }\end{array}$ & II. Orchiectomized & $\begin{array}{l}\text { III. Orchiectomized- } \\
\text { T.P. supplemented }\end{array}$ \\
\hline No. of adrenal & 9 & 8 & 8 \\
\hline Epinephrine $(\mu \mathrm{g})$ & $10.013 \pm 0.476$ & $10.942 \pm 0.587$ & $10.828 \pm 0.968$ \\
\hline$(\mu \mathrm{g} / \mathrm{mg}$ adrenal $)$ & $0.485 \pm 0.036$ & $0.443 \pm 0.020$ & $0.539 \pm 0.062$ \\
\hline No. of adrenal & 8 & 8 & 7 \\
\hline Norepinephrine $(\mu \mathrm{g})$ & $1.264 \pm 0.297^{\mathrm{b}}$ & $2.350 \pm 0.273$ & $1.532 \pm 0.240^{\mathrm{a}}$ \\
\hline ( $\mu \mathrm{g} / \mathrm{mg}$ adrenal) & $0.0596 \pm 0.0137^{a}$ & $0.0949 \pm 0.0105$ & $0.0764 \pm 0.0112$ \\
\hline No. of adrenal & 8 & 8 & 7 \\
\hline Total catecholamines $(\mu \mathrm{g})$ & $11.270 \pm 0.533^{\mathrm{a}}$ & $13.292 \pm 0.741$ & $12.262 \pm 0.894$ \\
\hline$(\mu \mathrm{g} / \mathrm{mg}$ adrenal $)$ & $0.557 \pm 0.034$ & $0.538 \pm 0.023$ & $0.6134 \pm 0.068$ \\
\hline
\end{tabular}

* Mean \pm S.E.

a,b Significantly different from II, $\mathrm{p}<0.05$ and 0.02 respectively, 


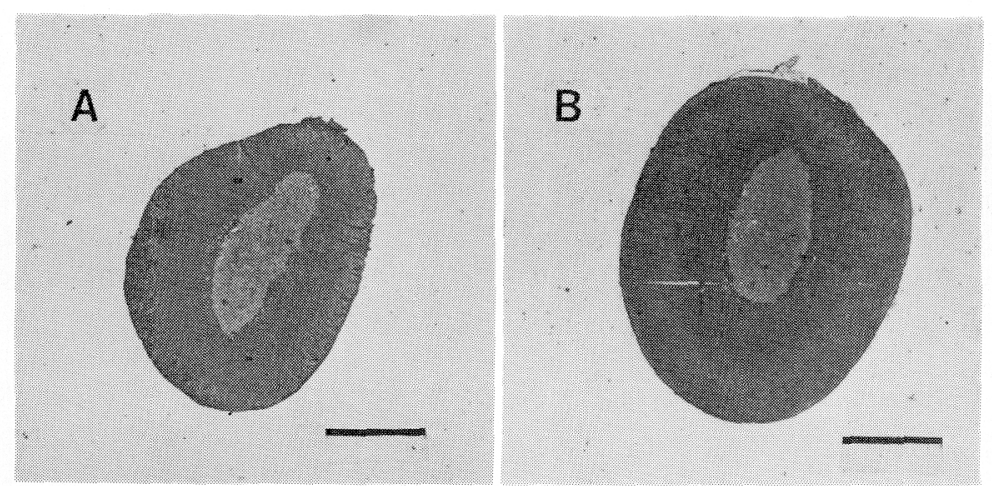

Fig. 1 Transverse sections, along the major axis, $10 \mu$ thick, which are the longest. The sections are stained with hematoxylin and eosin. A: the control adrenal; B: the adrenal from the orchiectomized rat. Note the hypertrophy of $\mathrm{B}$.

was also noticed. In general, the adrenal cortex of B appeared to be full of hypertrophied parenchymal cells as well as in the medulla.

The volume of the adrenal cortex and medulla from the control and orchiectomized rats is shown in Table 4 . The whole adrenal and cortex volumes were clearly increased by $45 \%$ and $47 \%$ of control volumes respectively, after orchiectomy (Table 4). The mean medullary volume in question also tended to increase by $33 \%$ of control though it was not significant. The ratio of the medullary volume to that of the cortex, however, did not change significantly. This indicates that orchiectomy caused the hypertrophy of not only the

Table 4. Effect of orchiectomy and T.P. supplement on the volume of the adrenal cortex and medulla

\begin{tabular}{lcc}
\hline & $\begin{array}{c}\text { I. Sham- } \\
\text { operated }\end{array}$ & $\begin{array}{c}\text { II. Orchiec- } \\
\text { tomized }\end{array}$ \\
\hline $\begin{array}{l}\text { No. of adrenals } \\
\text { Whole adrenal } \\
\left(\mathrm{mm}^{3}\right)\end{array}$ & $9.390 \pm 1.112$ & $13.645 \pm 0.790^{\mathrm{a}}$ \\
$\begin{array}{c}\text { Adrenal cortex } \\
\left(\mathrm{mm}^{3}\right)\end{array}$ & $8.688 \pm 1.094$ & $12.795 \pm 0.903^{\mathrm{a}}$ \\
$\begin{array}{c}\text { Adrenal medulla } \\
\left(\mathrm{mm}^{3}\right)\end{array}$ & $0.705 \pm 0.118$ & $0.940 \pm 0.131$ \\
$\begin{array}{c}\text { Medulla/cortex } \\
\left(\mathrm{mm}^{3} / \mathrm{mm}^{3}\right)\end{array}$ & $0.085 \pm 0.020$ & $0.077 \pm 0.017$ \\
\hline
\end{tabular}

a, Significantly different from I, p $<0.05$. adrenal cortex but also the medulla to a smaller extent than that of the cortex.

\section{Discussion}

In the present experiment, the effect of orchiectomy and T.P. supplement on the weight of not only the pituitary and adrenal but also the thymus was confirmed as previously described (Kitay, 1963b). Plasma corticosterone concentration was not altered by orchiectomy and T.P. supplement, which represented strictly a resting level because dexamethazone-pentobarbiturate primed rats were used in this experiment. Although adrenal corticosterone content in the resting level $(\mu \mathrm{g} / \mathrm{mg}$ adrenal) was not changed by orchiectomy, it was increased significantly when expressed in terms of total content and the increase was prevented by T.P. supplement. However, a precursor substance of the hormone, cholesterol, was increased after orchiectomy per mg tissue weight and the increase was prevented by the T.P. supplement as reported by Kitay et al. (Kitay et al., 1966). It is interesting that the pool size of adrenal corticosterone $(\mu \mathrm{g} / \mathrm{mg}$ adrenal) in the resting state was not altered by orchiectomy and T.P. supplement while the cholesterol content $(\mu \mathrm{g} / \mathrm{mg}$ adrenal) was 
changed markedly.

Histological observation revealed that the adrenal medulla was also hypertrophied after orchiectomy as well as the cortex (Fig. 1B). An approximate and conventional method employed in the present study to estimate the volume of the adrenal cortex and medulla showed a clear increase in cortical volume and also an increase in the volume of the medulla after orchiectomy though the latter increase was not statistically significant. The ratio of the medullary volume to that of the cortex, however, did not change significantly after orchiectomy, indicating a probable increase in the medullary volume.

Evidence is also presented by the results obtained in estimating catecholamine concentrations (Table 3). Orchiectomy resulted in increased total catecholamines and norepinephrine contents and T.P. supplement prevented the increase of norepinephrine which is a minor component of the medullary hormone. These results indicate that the medullary function is also variable, with a concurrent change in that of cortex. It is interesting that orchiectomy induced a selective increase in norepinephrine rather than epinephrine (Table 3). These relevant results indicate that the concomitant change in the adrenal medulla was caused by androgens with that in the cortex. Since functional change in the medulla was not dealt with in this experiment, a further study will be required, because it is important to inves- tigate the functional interrelation between both the tissues which are fused and may interact each other.

\section{Acknowledgements}

The authors are greatly indebted to $\mathrm{Mr}$. T. Kagekawa and Mrs. K. Shibasaki-Ieiri for technical assistance.

\section{References}

Clark, B. R., R. T. Rubin and R. J. Arthur (1968). Anal. Biochem. 24, 27.

Colby, H. D. and J. I. Kitay (1972). Proc. Soc. Exptl. Biol. \& Med. 140, 1.

Crout, R. J. (1962). In Fluorescence Assay in Biology and Medicine, ed. by Udenfriend S., Academic Press, New York, pp. 139.

Kitay, J. I. (1961). Endocrinology 68, 818.

Kitay, J. I. (1963a). Ibid. 72, 949.

Kitay, J. I. (1963b). Ibid. 73, 253.

Kitay, J. I. (1963c). Acta Endocrinologica 43, 601.

Kitay, J. I., M. D. Coyne, R. Nelson and W. Newsom (1966). Endocrinology 78, 1061. Moncloa, F., F. G. Peron and R. T. Dorfman (1959). Ibid. 65, 717.

Tanaka, A. and M. Nakamura (1968). In Integrative Mechanism of Neuroendocrine System, ed. by Itoh S., Hokkaido Univ. Med. Library Series I, Sapporo, pp. 49-62. 